\title{
Subject Index to Volume 29 - 2002
}

\section{ABSTRACTS}

Abstracts: 37 th Meeting of the Canadian Congress of Neurological Sciences

Abstracts: Canadian Association of

Neuropathologists: 4 Ist Annual Meeting394 (NOV)

\section{AGING}

The Impact of Aging on Vasa Nervorum, Nerve Blood

Flow and Vasopressin Responsiveness 164 (MAY)

AIDS

The Neuropathogenesis of HIV Infection: Host-Virus Interaction and the Impact of Therapy 19 (FEB)

ALZHEIMER'S

Treatment of Alzheimer's Disease and Other Dementias - Review and Comparison of the Cholinesterase Inhibitors 306 (NOV)

ANEURYSMS

Non-Atherosclerotic Fusiform Cerebral Aneurysms

41 (FEB)

Non-Atherosclerotic Fusiform Aneurysms

5 (FEB)

ANGIOPLASTY

Carotid Stenting Without Angioplasty 175 (MAY)

ANOXIA

Neuroimaging Highlight

Global Cerebral Anoxia

88 (FEB)

AUTHORSHIP

Reporting Clinical Trials:

Full Access to All the Data

BRAIN TUMOURS

Single Dose versus Fractionated Stereotactic Radiotherapy for Meningiomas 240 (AUG)

Brain Metastasis from Prostate Small Cell

Carcinoma: Not to be Neglected 375 (NOV)

CAN. ASSOC. NEUROPATHOLOGISTS

Abstracts: 42nd Annual Meeting of the Canadian Association of Neuropathologists 394 (NOV)

CAROTID ARTERY DISSECTION

"Malignani" Carotid Artery Dissection

$378(\mathrm{NOV})$

CAROTID ENDARTERECTOMY

Auditing Carotid Endarterectomy A Regional Experience

Provincial Carotid Endarterectomy

Outcomes

333 (NOV)

\section{CAVERNOUS ANGIOMA}

Cavernous Malformation of the Hypoglossal Nerve: Case Report and Review of the Literature

191 (MAY)

\section{CAVERNOUS HEMANGIOMA}

Cavernous Malformation of the Hypoglossal Nerve: Case Report and Review of the Literature

\section{CEREBROVASCULAR DISEASE}

Non-Atherosclerotic Fusiform Aneurysms 5 (FEB) Idiopathic Free-Floating Thrombus of the Common Carotid Artery

Hypertension and Stroke

Blood Pressure Management in Acute Stroke: Comparison of Current Guidelines with Prescribing Patterns 113 (MAY)

Carotid Stenting Without Angioplasty

Adherence to Practice Guidelines for Transient Ischemic Attacks in an Emergency Department

125 (MAY)

175 (MAY)

358 (NOV)

Letter to the Editor

Management of Blood Pressure in Acute Stroke

\section{CLINICAL TRIALS}

Reporting Clinical Trials: Full Access to All the Data

4 (FEB)

CLUSTER HEADACHE

Cluster Headache: Evidence for a Disorder of Circadian Rhythm and Hypothalamic Function 33 (FEB)

CME

New Website for the Canadian Journal of Neurological Sciences is Up and Running

301 (NOV)

COMMUNICATION

The Communication of Neurological Bad News to Parents

$78(\mathrm{FEB})$

DEMENTIA

Treatment of Alzheimer's Disease and

Other Dementias - Review and Comparison

of the Cholinesterase Inhibitors

306 (NOV)

\section{DEPRESSION}

Depression et Maladie de Parkinson:

etude d'une serie de 135 parkinsoniens 139 (MAY)

\section{DISC HERNIATION}

Outpatient Lumbar Microdiscectomy:

A Prospective Study in 122 Patients 249 (AUG)

DISSECTION

Carotid Dissection: Technical Factors

Affecting Endovascular Therapy

$54($ FEB)

DOCTOR-PATIENT RELATIONSHIP

The Communication of Neurological

Bad News to Parents

78 (FEB)

DRIVING

Epilepsy and motor vehicle driving - A Symposium held in Quebec City, November 1998315 (NOV)

\section{EDITORIAL}

A New Year, A New Issue and Evolution of the Canadian Journal of Neurological Sciences

\section{EDUCATION}

Letter to the Editor

Education in the Clinical Neurosciences

Response to A. Buchan's Editorial

"Back to the Future"

Evidence Based Care in the Neurosciences) and An Evidence Based Approach to the First Unprovoked Seizure

115 (MAY

New Website for the Canadian Journal of Neurological Sciences

$301(\mathrm{NOV})$

ELECTROCORTICOGRAM

Cortical Location of Benign Paroxysmal Rhythms in the Electrocorticogram

154 (MAY)

\section{ELECTROENCEPHALOGRAPHY}

Clinical and Basic Neurophysiology of Generalised Epilepsies

Cortical Location of Benign Paroxysmal Rhythms in the Electrocorticogram 154 (MAY)

Canadian EEG Standards: A Quality Issue 205 (AUG)

Minimal Standards for Electroencephalography in Canada

ENCEPHALITIS

Nipah Encephalitis Outbreak in Malaysia: Clinical Features in Patients from Seremban 83 (FEB)

ENCEPHALOPATHY

Ifosfamide Encephalopathy and Nonconvulsive Status Epilepticus 180 (MAY)
EPILEPSY

Clinical and Basic Neurophysiology of Generalised Epilepsies

$6(\mathrm{FEB})$

Convulsive Status Epilepticus in Children) with Intractable Epilepsy is Frequently Focal in Origin

65 (FEB

ETHICS

A New Year, A New Issue and Evolution of the Canadian Journal of Neurological Sciences

Reporting Clinical Trials:

Full Access to All the Data

EVIDENCE BASED MEDICINE

Evidence Based Care in the Neurosciences and An Evidence Based Approach to the First Unprovoked Seizure

EXCHANGE ARTICLE

Nipah Encephalitis Outbreak in Malaysia Clinical Features in Patients from Seremban 83 (FEB)

EXERCISE

Lactate Stress Testing in 155

Patients with Mitochondriopathy

GENETICS - CLINICAI

Rett Syndrome: Investigation of Nine Patients, Including PET Scan

GLIOMA

Human Autologous In Vitro Models of Glioma Immunogene Therapy Using B7-2, GM-CSF, and ILI2

$267(\mathrm{AUG})$

HEAD TRAUMA

Reply to Letter to the Editor: Head Injuries in Skiers and Snowboarders 292 (AUG) Letter to the Editor: Head Injuries in Skiers and Snowboarders

HEADACHE

Cluster Headache: Evidence for a Disorder of Circadian Rhythm and Hypothalamic Function

Spontaneous Intracranial Hypotension in the Absence of Magnetic Resonance Imaging Abnormalities

Pneumocephalus as a Cause for Headache 278 (AUG)

Communication with the Migraine Patient SI (JUN)

Evaluating Migraine Disability: The Headache Impact Test Instrument in Context

SII (JUN) Assessing Health-Related Quality of Life in Patients with Migraine

S16(JUN)

Migraine: The Doctor-Patient Link Results of a Needs Assessment

Communicating the Right Therapy for the Right Patient at the Right Time: Acute Therapy

Improving Patient Compliance to Prophylactic Migraine Therapy

Communication Issues in Migraine Diagnosis

HEMIATROPHY

Hemiparkinsonism - Somatic Hemiatrophy Syndrome

HEMIPARESIS

Tests of Motor Function in Patients Suspected of Having Mild Unilateral Cerebral Lesions

$337(\mathrm{NOV})$

HEMORRHAGE

Non-Atherosclerotic Fusiform Cerebral Aneurysms 
Reversal of Normal Pressure Hydrocephalus Symptoms by Subdural Collections

171 (MAY)

\section{HISTORY}

Jules Bernard Luys: A Singular Figure of 19th Century Neurology

282 (AUG)

HIV

The Neuropathogenesis of HIV Infection: Host-Virus Interaction and the Impact of Therapy

AZT Myopathy and HIV-I Polymyositis: One Disease or Two?

19 (FEB) $390(\mathrm{NOV})$

\section{HIV-1 VIRUS}

The Neuropathogenesis of HIV Infection: Host-Virus Interaction and the Impact of Therapy 19 (FEB)

HOCKEY

An Unusual Presentation of Tarsal Tunnel Syndrome Caused by an Inflatable Ice Hockey Skate

$386(\mathrm{NOV})$

\section{HYDROCEPHALUS}

Reversal of Normal Pressure Hydrocephalus Symptoms by Subdural Collections

171 (MAY)

\section{HYPERTENSION}

Hypertension and Stroke

113 (MAY)

Blood Pressure Management in Acute Stroke: Comparison of Current Guidelines with Prescribing Patterns 125 (MAY) Letter to the Editor: Management of Blood Pressure in Acute Stroke

\section{IMMUNE SYSTEM}

Human Autologous In Vitro Models of Glioma Immunogene Therapy Using B7-2, GM-CSF, and IL12

\section{INFECTIONS OF THE NERVOUS SYSTEM}

Reply to a Letter to the Editor Intramedullary Spinal Tuberculoma and Syringomyelia

Intramedullary Spinal Tuberculoma and Syringomyelia

\section{INTERVENTIONAL NEURORADIOLOGY}

Carotid Dissection: Technical Factors Affecting Endovascular Therapy 54 (FEB) Carotid Stenting Without Angioplasty

"Malignant" Carotid Artery Dissection 175 (MAY) 378 (NOV)

\section{INTRACRANIAL PRESSURE}

Spontaneous Intracranial Hypotension in the Absence of Magnetic Resonance Imaging Abnormalities

$253(\mathrm{AUG})$

\section{ISCHEMIC BRAIN INJURY}

Neuroimaging Highlight: Accidental Hydrogen Peroxide Ingestion

$276(\mathrm{AUG})$

\section{LEUKODYSTROPHY}

Isolated Peripheral Neuropathy in Atypical Metachromatic Leukodystrophy: A Recurrent Mutation

\section{LEVODOPA}

The Clinical Profile of Nonmotor Fluctuations in Parkinson's Disease Patients 61 (FEB)

Respiratory Muscle Performance and the Perception of Dyspnea in Parkinson's Disease 68 (FEB)

Tapping and Peg Insertion after Levodopa Intake in Treated and de novo Parkinsonian Patients

\section{LIPOPROTEIN}

Status Epilepticus: A Critical Review of Management Options
LYMPHOMA

Multi-modality Therapy Leads to Longer Survival in Primary Central Nervous System Lymphoma Patients

147 (MAY)

MAGNETIC RESONANCE IMAGING

Neuroimaging Highlight

Global Cerebral Anoxia

88 (FEB)

\section{MEMORIAM}

Edward Bruce Hendrick

January 20,1924 - August 17, $2001 \quad 100$ (FEB)

Theodore Rasmussen, $1910-2002 \quad 289$ (AUG)

Husam Zaki Darwish

291 (AUG)

Delbert G. Wollin, MD, $1913-2002 \quad 402$ (NOV)

\section{MENINGIOMAS}

Single Dose versus Fractionated Stereotactic

Radiotherapy for Meningiomas

240 (AUG)

\section{MIGRAINE}

Communication with the Migraine Patient S) (JUN) Evaluating Migraine Disability: The Headache Impact Test Instrument in Context S11 (JUN)

Assessing Health-Related Quality of Life in Patients with Migraine

Migraine: The Doctor-Patient Link Results of a Needs Assessment

Communicating the Right Therapy for the Right Patient at the Right Time: Acute Therapy

Improving Patient Compliance to Prophylactic Migraine Therapy

Communication Issues in Migraine Diagnosis

S16 (JUN)

S3 (JUN)

S33 (JUN)

S40 (JUN)

S8 (JUN)

\section{MITOCHONDRIAL DISORDER}

Lactate Stress Testing in 155

Patients with Mitochondriopathy

49 (FEB)

\section{MOLYBDENUM}

New Insights into the Neuropathogenesis of Molybdenum Cofactor Deficiency

91 (FEB)

\section{MOTOR CONTROL}

Tapping and Peg Insertion after Levodopa Intake in Treated and de novo Parkinsonian Patients

Tests of Motor Function in Patients Suspected of Having Mild Unilateral Cerebral Lesions

\section{MOTOR FLUCTUATIONS}

The Clinical Profile of Nonmotor Fluctuations in Parkinson's Disease Patients 61 (FEB)

\section{MOVEMENT DISORDERS}

"Stiff in the Closet" - Who Provides Care for Parkinsonian Patients? Parkinsonism in Ontario: Physician Utilization

221 (AUG)

\section{MYOPATHY}

Lactate Stress Testing in 155 Patients with Mitochondriopathy AZT Myopathy and HIV-1 Polymyositis: One Disease or Two?

390 (NOV)

\section{MYOTONIC DYSTROPHY}

A Patient with Proximal Myotonic Myopathy and Parkinsonism

188 (MAY)

\section{NERVE BLOOD FLOW}

The Impact of Aging on Vasa Nervorum, Nerve Blood Flow and Vasopressin Responsiveness 164 (MAY)

\section{NEURO-ONCOLOGY}

Management of Optic Chiasmatic/Hypothalamic Astrocytomas in Children
Multi-modality Therapy Leads to Longer Survival in Primary Central Nervous System Lymphoma Patients 147 (MAY) Single Dose versus Fractionated Stereotactic Radiotherapy for Meningiomas 240 (AUG)

Human Autologous In Vitro Models of Glioma Immunogene Therapy Using B7-2, GM-CSF, and ILI2 267 (AUG)

Brain Metastasis from Prostate Small Cell Carcinoma: Not to be Neglected 375 (NOV)

\section{NEUROLOGICAL EXAMINATION}

Tests of Motor Function in Patients Suspected of Having Mild Unilateral Cerebral Lesions 337 (NOV)

\section{NEUROLOGICAL PRACTICE}

New Website for the Canadian Journal of Neurological Sciences

$301(\mathrm{NOV})$

Communication with the Migraine Patient S1 (JUN)

Doctor-Patient Communication: Principles and Practices

S23 (JUN)

Migraine: The Doctor-Patient Link Results of a Needs Assessment Bridges and Bridging Barriers

Communication Issues in Migraine

Diagnosis

S30 (JUN)

EUROLOGY - GENERAL

Jules Bernard Luys: A Singular Figure of 19 th Century Neurology

\section{NEUROLOGY - PAEDIATRIC}

Convulsive Status Epilepticus in Children with Intractable Epilepsy is Frequently Focal in Origin

New Insights into the Neuropathogenesis of Molybdenum Cofactor Deficiency Management of Optic Chiasmatic/Hypothalamic Astrocytomas in Children

Memoriam: Husam Zaki Darwish

Rett Syndrome: Investigation of Nine Patients, Including PET Scan
aunching a Research Initiative: The Canadian Pediatric Epilepsy Network (CPEN) $\quad 364$ (NOV)

\section{NEUROPATHY}

An Unusual Presentation of Tarsal Tunnel Syndrome Caused by an Inflatable Ice Hockey Skate $386(\mathrm{NOV})$

\section{NEUROPATHY - PERIPHERAL}

Electronic Case-Report Forms of Symptoms and Impairments of Peripheral Neuropathy 258 (AUG) An Unusual Presentation of Tarsal Tunnel Syndrome Caused by an Inflatable lce Hockey Skate

$386(\mathrm{NOV})$

\section{NEUROPSYCHOLOGY-EPILEPSY}

Evidence Based Care in the Neurosciences and An Evidence Based Approach to the First Unprovoked Seizure 115 (MAY) Canadian EEG Standards: A Quality Issue 205 (AUG) Status Epilepticus: A Critical Review of Management Options 206 (AUG)

Minimal Standards for Electroencephalography in Canada 216 (AUG)

Epilepsy and motor vehicle driving A Symposium held in Quebec City, November 1998 315 (NOV)

Launching a Research Initiative: The Canadian Pediatric Epilepsy Network (CPEN) 364 (NOV)

\section{NEURORADIOLOGY}

Carotid Dissection: Technical Factors Affecting Endovascular Therapy 


\section{NEUROSURGERY}

Edward Bruce Hendrick

January 20, 1924 - August 17, 2001 100 (FEB)

Outpatient Lumbar Microdiscectomy:

A Prospective Study in 122 Patients 249 (AUG)

In Memoriam:

Theodore Rasmussen, $1910-2002 \quad 289$ (AUG)

NEUROSURGERY - ADULT

Neuroimaging Highlight: Petrous Apex Granulomas: CT and MRI Imaging

169 (MAY)

Reversal of Normal Pressure Hydrocephalus Symptoms by Subdural Collections 171 (MAY)

Outpatient Lumbar Microdiscectomy:

A Prospective Study in 122 Patients 249 (AUG)

Provincial Carotid Endarterectomy

Outcomes

333 (NOV)

\section{NEUROSURGERY - PAEDIATRIC}

Edward Bruce Hendrick

January 20, 1924 - August 17,2001 100 (FEB)

Management of Optic Chiasmatic/Hypothalamic Astrocytomas in Children

132 (MAY)

NEUROSURGERY - VASCULAR

Carotid Dissection: Technical Factors Affecting Endovascular Therapy

Idiopathic Free-Floating Thrombus of the Common Carotid Artery

97 (FEB)

\section{NEUROSURGICAL PRACTICE}

Outpatient Lumbar Microdiscectomy: A Prospective Study in 122 Patients 249 (AUG)

New Website for the Canadian Journal of Neurological Science

301 (NOV)

Auditing Carotid Endarterectomy: A Regional Experience

Provincial Carotid Endarterectomy Outcomes

NEUROVIROLOGY

Nipah Encephalitis Outbreak in Malaysia: Clinical Features in Patients from Seremban

83 (FEB)

\section{NIPAH ENCEPHALITIS}

Nipah Encephalitis Outbreak in Malaysia: Clinical Features in Patients from Seremban

\section{PAEDIATRICS}

The Communication of Neurological Bad News to Parent.

New Insights into the Neuropathogenesis of Molybdenum Cofactor Deficiency

91 (FEB)

\section{PARKINSON'S DISEASE}

The Clinical Profile of Nonmotor Fluctuations in Parkinson's Discase Patients

Respiratory Muscle Performance and the Perception of Dyspnea in Parkinson's Disease

68 (FEB)

Tapping and Peg Insertion after Levodopa Intake in Treated and de novo Parkinsonian Patients

Depression et Maladie de Parkinson: etude d'une serie de 135 parkinsoniens

"Stiff in the Closet" - Who Provides Care for Parkinsonian Patients?

139 (MAY)

kinsonism in Ontario:

Physician Utilization
PARKINSONISM

Hemiparkinsonism - Somatic Hemiatrophy Syndrome

A Patient with Proximal Myotonic Myopathy and Parkinsonism

188 (MAY)

PERIPHERAL NERVE

Electronic Case-Report Forms of Symptoms and Impairments of Peripheral Neuropathy 258 (AUG)

\section{PERIPHERAL NEUROPATHY}

Isolated Peripheral Neuropathy in

Atypical Metachromatic Leukodystrophy:

A Recurrent Mutation

159 (MAY)

Electronic Case-Report Forms of Symptoms and Impairments of Peripheral Neuropathy 258 (AUG)

PET SCANNING

Rett Syndrome: Investigation of Nine

Patients, Including PET Scan

$345(\mathrm{NOV})$

PNEUMOCEPHALUS

Pneumocephalus as a Cause for Headache 278 (AUG)

\section{RADIATION}

Single Dose versus Fractionated Stereotactic

Radiotherapy for Meningiomas 240 (AUG)

RADIATION ONCOLOGY

Single Dose versus Fractionated Stereotactic

Radiotherapy for Meningiomas 240 (AUG)

RESPIRATORY

Respiratory Muscle Performance and the Perception of Dyspnea in Parkinson's Disease

68 (FEB)

\section{RETT SYNDROME}

Rett Syndrome: Investigation of Nine Patients, Including PET Scan

345 (NOV)

\section{SEIZURES}

Clinical and Basic Neurophysiology of Generalised Epilepsies

6 (FEB)

Convulsive Status Epilepticus in Children with Intractable Epilepsy is Frequently Focal in Origin

Evidence Based Care in the Neurosciences and An Evidence Based Approach to the First Unprovoked Seizure

115 (MAY)

Ifosfamide Encephalopathy and Nonconvulsive Status Epilepticus

180 (MAY)

Status Epilepticus: A Critical Review of Management Options

206 (AUG)

Epilepsy and motor vehicle driving A Symposium held in Quebec City, November 1998

315 (NOV)

SLEEP

Cluster Headache: Evidence for a Disorder of Circadian Rhythm and Hypothalamic Function

33 (FEB)

\section{SPINAL CORD}

Reply to a Letter to the Editor Intramedullary Spinal Tuberculoma and Syringomyelia

102 (FEB)

Intramedullary Spinal Tuberculoma and Syringomyelia

102 (FEB)

High-Dose Methylprednisolone for Acute Closed Spinal Cord Injury - Only a Treatment Option

227 (AUG)

Methylprednisolone for Acute Spinal Cord Injury A Canadian Perspective and a Position Statement

236 (AUG)
SPINAL CORD INJURY

High-Dose Methylprednisolone for Acute Closed Spinal Cord Injury - Only a Treatment Option

Methylprednisolone for Acute Spinal Cord Injury - A Canadian Perspective and a Position Statement

\section{STATUS EPILEPTICUS}

Convulsive Status Epilepticus in Children with Intractable Epilepsy is Frequently Focal in Origin

65 (FEB)

STENT

Carotid Stenting Without Angioplasty

175 (MAY)

STROKE

Idiopathic Free-Floating Thrombus of the Common Carotid Artery

Hypertension and Stroke

97 (FEB)

Blood Pressure Management in Acute Stroke: Comparison of Current Guidelines with Prescribing Patterns 125 (MAY) Neuroimaging Highlight: Accidental Hydrogen Peroxide Ingestion

276 (AUG)

Auditing Carotid Endarterectomy: A Regional Experience

326 (NOV)

Provincial Carotid Endarterectomy Outcomes

333 (NOV)

Adherence to Practice Guidelines for Transient Ischemic Attacks in an Emergency Department

358 (NOV)

378 (NOV)

"Malignant" Carotid Artery Dissection

etter to the Editor: Management of Blood Pressure in Acute Stroke

404 (NOV)

\section{SUBDURAL HEMATOMA}

Reversal of Normal Pressure Hydrocephalus Symptoms by Subdural Collections

$171(\mathrm{MAY})$

Treatment of Alzheimer's Disease and Other Dementias - Review and Comparison of the Cholinesterase Inhibitors

$306(\mathrm{NOV})$ TIA

Adherence to Practice Guidelines for Transient Ischemic Attacks in an Emergency Department

358 (NOV)

TRAUMA

High-Dose Methylprednisolone for Acute Closed Spinal Cord Injury - Only a Treatment Option

227 (AUG)

Methylprednisolone for Acute Spina Cord Injury - A Canadian Perspective and a Position Statement

Letter to the Editor: Head Injuries in Skiers and Snowboarders

Reply to Letter to the Editor: Head Injuries in Skiers and Snowboarders

TUBERCULOSIS

Intramedullary Spinal Tuberculoma and Syringomyelia

102 (FEB)

Reply to a Letter to the Editor Intramedullary Spinal Tuberculoma and Syringomyelia

102 (FEB) 